Volume 9, No.4, July - August 2020

International Journal of Advanced Trends in Computer Science and Engineering

Available Online at http://www.warse.org/IJATCSE/static/pdf/file/ijatcse85942020.pdf

https://doi.org/10.30534/ijatcse/2020/85942020

\title{
Wireless Sensor Networks based Intelligent Localization in Hostile Environment for Energy Conservation
}

\author{
P Shyamala Bharathi $^{1}$, C V Venkatasamy ${ }^{2}$, K Latha $^{3}$, K Shyamala ${ }^{4}$, G Ramprabu $^{5}$ \\ ${ }^{1}$ Assistant Professor, Department of Electronics and Communication Engineering, Saveetha School of \\ Engineering, Chennai, India \\ ${ }^{2}$ Associate Professor, Department of Electronics and Communication Engineering, Mailam Engineering College, \\ Mailam, Tamil Nadu, India \\ ${ }^{3}$ Assistant Professor, Department of Computer Science and Engineering, Sri Sairam Engineering College, \\ Chennai, India \\ ${ }^{4}$ Assistant Professor, Department of Electronics and Communication Engineering, Holy Mary Institute of \\ Technology \& Science, Hyderabad, Telangana, India \\ ${ }^{5}$ Professor, Department of Electronics and Communication Engineering, Bonam Venkata Chalamayya Institute of \\ Technology and Science, Amalapuram, India
}

\begin{abstract}
Wireless sensor networks (WSNs) have been widely utilized into armed application towards outskirt territory observing, war zone reconnaissance, following foe troop, however the sensor node runs with battery powers. Confinement of sensor node has been critical for distinguishing the position of occasion in armed application towards additional activities. Current confinement calculations devour additional vitality through substantial calculation as well as correspondence overhead. The goal of the projected framework helps building the duration of the armed sensor network through lessening the force utilization within every sensor nodes in limitation. Let's recommend a calculation to find the locality of sensor nodes alongside intelligent unmanned vehicle anchor node (IUAN).The intelligent unmanned vehicle anchor node gathers the sign quality, distancing information as of sensor node as well as the central control station (CCS) registers the situation of sensor node utilizing ILA calculation. These calculations give proficiency through diminishing calculation as well as correspondence rate contrasted with the straight quest utilized to find the crossing points upon the curve.
\end{abstract}

Key words: Wireless Sensor Networks, Hostile Environment and Energy Conservation.

\section{INTRODUCTION}

Wireless Sensor Network talks about assembling of dimensionally distributed as well as dedicated sensor towards observing also documenting the state of being of natural as well as cataloging the collected data on a central location. Wireless Sensor Network measures normal criteria such as temperatures, sounds, contaminated level, dampness, windy speeds as well as course, pressurized level, and so on. A Wireless Sensor Network comprises of anyplace as of a couple hundred till thousand of sensor node. The sensor nodes gear incorporates a radio handset alongside a receiving wire, microcontrollers, connecting electronic circuits, as well as a vitality sources, generally batteries.

Wireless Sensor Network is helpful into various regions, for example, catastrophic event the board frameworks, woodland fire location, sea route, mechanical computerization and control, and so on. WSN offers numerous types of assistance to military and Air Force like outskirt territory checking, data assortment, combat zone observation, location of interruptions and assaults. Existing research clarified the uses of sensor network as well as factor impacting the Wireless Sensor Network plan. The sorts of Wireless Sensor Networks, its working frameworks as well as stages, principles, information stockpiling strategies, power the board, task dissemination, information accumulation, security systems.

WSN is an assortment of sensor node as well as vitality absence of solitary sensor nodes cause serious effects. Sensor node battery's vitality has been expended into dynamic modes inert modes also rest mode. Portability dependent vitality preservation plans utilizing versatile sink-based and versatile transfer based methodologies is a whole number programming model for improving vitality utilization. The way toward evaluating the physically located sensor node has been localized as well as this has been significant like the detected information gets insignificant not including the locality of the occasion. 
P Shyamala Devi et al., International Journal of Advanced Trends in Computer Science and Engineering, 9(4), July - August 2020, 4783 - 4787

\section{RELATED WORK}

The itemized arrangement of the localization calculations has been clarified with Han [1] clarified the centralized as well as circulated localization plans. Current localization calculations expend more vitality by substantial calculation and correspondence overheads; accordingly drain the sensor node batteries rapidly. Yick [2] projected localization conspire through guide booking while every sensor nodes execute substantial calculations for deciding its location.

Portable anchor node-dependent localization projected with Anastasi [3] demands correspondence among sensor node throughout localization, where it sources delaying, information misfortune as well as higher vitality utilization.

Higher reference point operating cost localization plot has been specified through Aguiar [4] projected a localization conspire that includes between sensor interchanges as well as projected a localization plot that includes anchored order stage, distancing estimated stage as well as locality estimated stage. Into [5], fake neural system helped node's restriction has been projected towards evaluating the locality blunders utilizing counterfeit neural model.

Pescaru as well as Curiac projected anchored node-dependent localization towards Wireless Sensor Network utilizing visual as well as scope data combination. [6] Projected a versatile anchored-helped localization calculation. Higher correspondence as well as computing overheads decreases the general duration of Wireless Sensor Network [7]. Several methodologies within Wireless Sensor Network should moderate the batteries vitality of sensor node [8]. The authors projected an intelligent unmanned vehicle anchor node approaches by IAS calculation toward save vitality into every sensor nodes for expanding the existence season of armed sensor network $[9,10]$.

\section{PROPOSED SYSTEM}

The UAV could speed up and communicate reference points upon its personal vitality. UAVs would convey situating gadget as well as transmits toward limit the sensor node. The localization utilizing global positioning system (GPS) empowered speeding up anchor node. The UAVs toward disseminate the vitality trouble over the Wireless Sensor Network. Their fundamental thought is such that it should gather the locality as well as distancing information as of the sensor node also processes its locality. This methodology, UAV has been engaged by insight as well like used as speeding up anchor nodes.

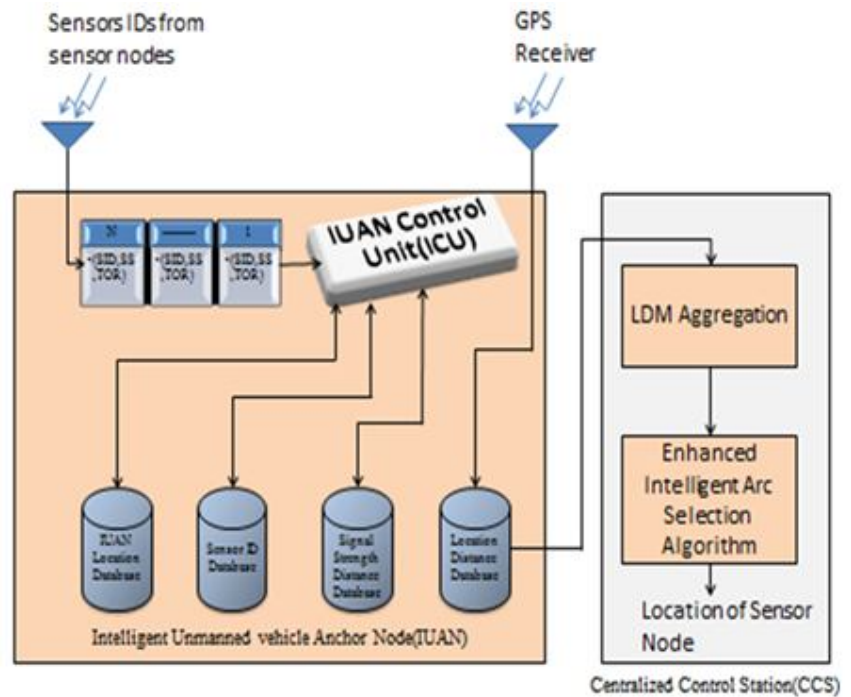

Figure 1: System Architecture

The intelligent unmanned vehicle anchor node has IUAN control unit (ICU), sensor ID databases $\left(\mathrm{DB}_{\mathrm{SID}}\right)$, visitor queues (VQ), signal strengthening-distance database $\left(\mathrm{DB}_{\mathrm{SSD}}\right)$, IUAN locality databases ( $\left.\mathrm{DB}_{\mathrm{ILOC}}\right)$ and location-distance database $\left(\mathrm{DB}_{\mathrm{LD}}\right)$. The IUAN control units control the general activity of the intelligent unmanned vehicle anchor node as accepting sensor identity (SID) as of sensor node, actuating global positioning system beneficiaries, correspondence by central control station, directing the intelligent unmanned vehicle anchor node in a hopeful direction. At the point while an intelligent unmanned vehicle anchor node goes in the broadcast scope of sensor nodes, the sensor nodes communicate their sensor identity towards its intelligent unmanned vehicle anchor node as well as the IUAN control unit performs the grouping of procedures for building the location-distance message (LDM). Intelligent unmanned vehicle anchor node might get the sensor identity as of different sensor node as well as the Visitor Queues store the sensor identity alongside its signal strength (SSs) also comparing season of gathering Sensor Identity ${ }_{\text {TOR. Sensor }}$ Identity unmanned vehicle anchor node obtains the Sensor Identity. Every time the intelligent unmanned vehicle anchor node gets the Sensor Identity (on $\mathrm{TOR}_{\mathrm{SID}}$ ), this saves the Sensor Identity, their self locality $\left(\mathrm{LOC}_{\mathrm{IUAN}}\right)$ including $\mathrm{TOR}_{\mathrm{IUAN}}$ toward the $\mathrm{DB}_{\mathrm{ILOC}}$ such as $\mathrm{TOR}_{\mathrm{IUAN}}=\mathrm{TOR}_{\mathrm{SID}}$. The Table 1 provides the structuring of the $\mathrm{DB}_{\mathrm{ILOC}}$.

The intelligent unmanned vehicle anchor node validates the Sensor Identities into the Visitor Queue utilizing the $\mathrm{DB}_{\mathrm{SID}}$ since $\mathrm{DB}_{\mathrm{SID}}$ have substantial SID number. The void Sensor Identities is disregarded as well as Location Distance message is developed in support of just the legitimate sensor node. The $\mathrm{DB}_{\mathrm{SSD}}$ has been utilized for surviving through radio abnormality. The sign quality on the locality about the broadcast scope of sensor nodes differs by the distancing as well as natural impacts. The way misfortune impact makes the radio sign lessen differently in various ways. The Table 2 
P Shyamala Devi et al., International Journal of Advanced Trends in Computer Science and Engineering, 9(4), July - August 2020, 4783 - 4787

illustrates the structural design of $\mathrm{DB}_{\mathrm{SSD}}$ by test estimations of the Signal Strengths (SSs) by $3.048 \mathrm{~m}$ far as of the mica2 bit into four ways. The Signal Strength has been determined dependent over signal quality distancing connection utilizing received signal strength indication (RSSI) estimations by the information on degree of irregularity (DOI).

\begin{tabular}{|c|c|c|}
\hline $\begin{array}{l}\text { Time of IUAN location } \\
\text { reception } \\
\text { TOR } \\
\text { =TORAN (where TOR } \\
\text { TORAN }\end{array}$ & SID & $\begin{array}{c}\text { Location of } \\
\text { IUAN } \\
\text { (LOCIUAN) }\end{array}$ \\
\hline & SID & \\
\hline $\mathrm{T}_{1}$ & $\begin{array}{l}1 \\
\text { SID }\end{array}$ & $\left(\mathrm{x}_{1}, \mathrm{y}_{1}\right)$ \\
\hline $\mathrm{T}_{2}$ & $\begin{array}{l}1 \\
\text { SID }\end{array}$ & $\left(\mathrm{x}_{2}, \mathrm{y}_{2}\right)$ \\
\hline $\mathrm{T}_{3}$ & 1 & $\left(\mathrm{x}_{3}, \mathrm{y}_{3}\right)$ \\
\hline & SIN & $\left(\mathrm{x}_{\mathrm{n}}, \mathrm{y}_{\mathrm{n}}\right)$ \\
\hline
\end{tabular}

Table 2: RSSI value and distance of signal strength-distance

\begin{tabular}{ccc}
\multicolumn{3}{c}{ database (DB $\left.{ }_{\text {SSD }}\right)$} \\
\hline $\begin{array}{c}\text { Signal strength } \\
\text { (SS) }\end{array}$ & Distance (D) & \\
& & Direction \\
(dBm) & $(\mathbf{m})$ & \\
\hline-63 & 3.048 & East \\
-59 & 3.048 & North \\
-58 & 3.048 & West \\
-57 & 3.048 & South \\
\hline
\end{tabular}

Towards a legitimate Sensor Identity, an intelligent unmanned vehicle anchor node brings the distance (D) among its own as well as the sensor nodes utilizing the relating $\mathrm{SS}_{\mathrm{SID}}$. This methodology, the calculation costs of the sign quality as well as distancing estimations was moved as of the sensor node towards the amazing intelligent unmanned vehicle anchor node for preserving the vitality on every sensor nodes. At some point in the approval of Sensor Identity as well as distancing-getting procedure, the intelligent unmanned vehicle anchor node progresses towards various localities. Consequently in the wake of getting the distance, the intelligent unmanned vehicle anchor node gets the relating locality information $\left(\mathrm{LOC}_{\mathrm{IUAN}}\right)$ where this received the Sensor Identity, utilizing the TOR $_{\text {IUAN }}$ along with TOR $\mathrm{SID}_{\text {. }}$ These component guarantees the assortment of substantial locality as well as distancing data. The intelligent unmanned vehicle anchor node builds the location-distance message also saves this within the DBLD databases, so that each LDM has the locations (L), distances (D) as well as the comparing Sensor Identity.
Table 3: Lists of symbol utilized into Location Distance message structure algorithms

\begin{tabular}{ll}
\hline \multicolumn{1}{c}{ Symbol } & \multicolumn{1}{c}{ Definition } \\
\hline IUAN & Intelligent UAV anchor node \\
$\Delta(f)$ & Flight period of IUAN \\
SID & Sensor ID sent by the sensor node \\
TORSID & Time of SID reception \\
TORIUAN & Time at which the IUAN location is \\
& received from GPS \\
VQ & Visitor queue \\
DBSID & Sensor ID database \\
DBSSD & Signal strength-distance database \\
DEILOC & IUAN location database \\
DBID & Location-distance database \\
SSSID & Signal strength of SID \\
D & Distance between sensor node and IUAN \\
& at TORSID \\
LOCIUAN & Location of the IUAN when ir receives \\
the SID & Location-distance message \\
LDM & Procedure to construct LDM with 'D', \\
ConstructLDMPacket & 'LOCiUAN' and 'SID' \\
(LOCIUAN, D, SID) &
\end{tabular}

The Table 3 illustrates the rundown of images utilized within the LDM development calculation (Algorithms 1) as well as comparing stream graph has appeared into Figure 2. Subsequent to developing the LDM, the IUAN control unit expels the comparing passages as of the Visitor Queue as well as IUAN location database for dealing with the capacity productivity. The intelligent unmanned vehicle anchor node builds the LDM as well as arrives at the central control station, such that central control station totals DBLD databases of the entire IUAN also chooses the adequate LDM for ascertaining the locality of the sensor node. On the off chance that an intelligent unmanned vehicle anchor node (state intelligent unmanned vehicle anchor node -100) are potted somewhere around foes, this promptly sends their slammed codes towards the close by sensor nodes (state Sensor Node-51).

At the point while an additional intelligent unmanned vehicle anchor node (state IUANs-200) arrives at Sensor Node-51 afterward, this sends the slammed codes of intelligent unmanned vehicle anchor node -100 towards intelligent unmanned vehicle anchor node -200. As soon as intelligent unmanned vehicle anchor node -200 arrives at central control station, this distinguishes so that the intelligent unmanned vehicle anchor node -100 has been slammed through the foes. 


\section{Algorithm 1: LDM Construction}

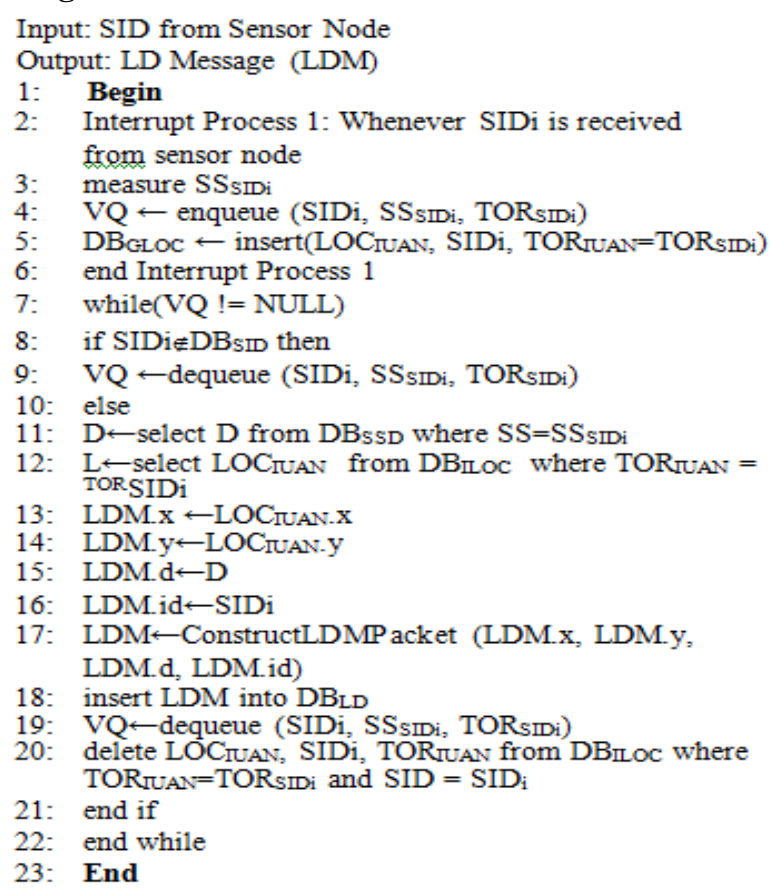

\section{Intelligent Localization Algorithm}

Our methodology figures the locality of sensor node on central control station whereas the registering as well as correspondence assets hasn't been the requirement. The projected calculation totals the LDMs as of various intelligent unmanned vehicle anchor node as well as processes the locality of a sensor nodes by three significant LDM. All the LDMs have the LOC-IUAN as well as distancing among the LOC-IUAN also relating sensor nodes locality.

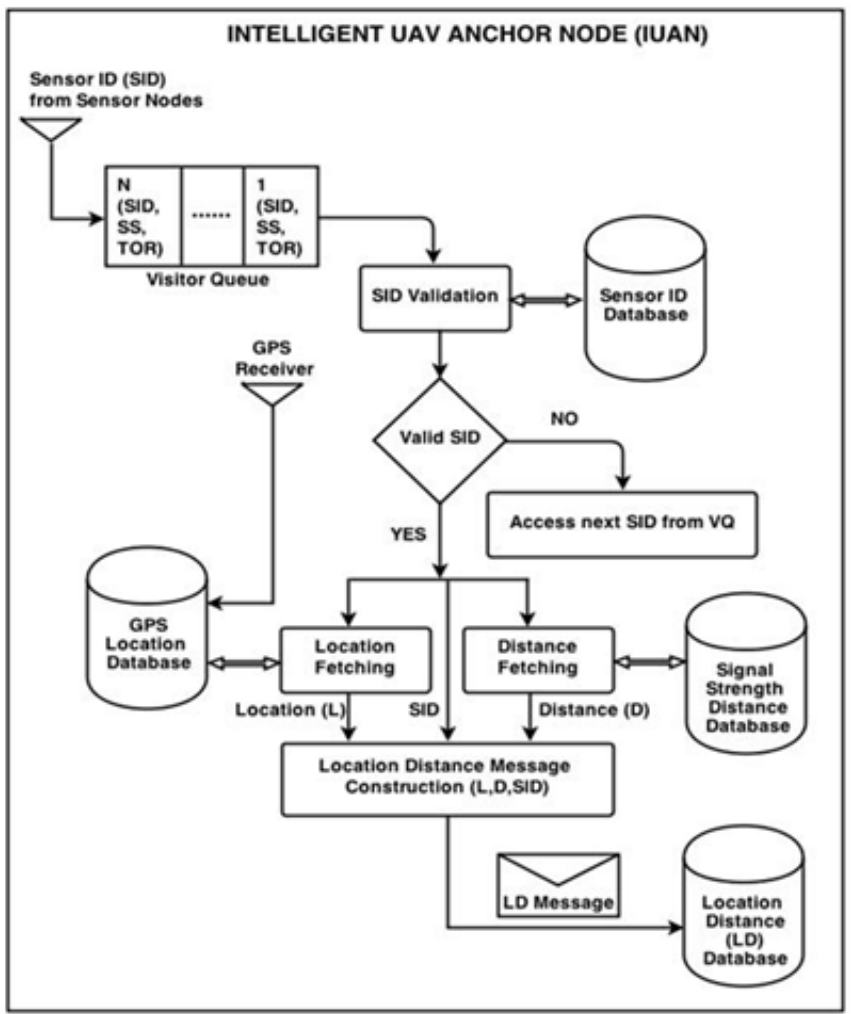

Figure 2: Flow Diagram of Location Distance Message structure Algorithm

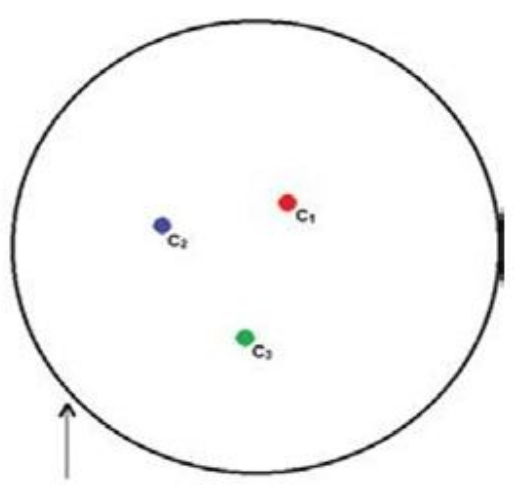

Figure 3: Communicating ranges of sensor nodes

Three LD messages collected within the range of a sensor node.

At the point when the intelligent unmanned vehicle anchor node arrives at the broadcast scope of the sensor nodes and this SN transmits communication toward the intelligent unmanned vehicle anchor nodes. The locality where the intelligent unmanned vehicle anchor node gets the communication, the distances among the intelligent unmanned vehicle anchor node as well as the $\mathrm{SN}$ has been determined within IUANs. In light of these data LDM messages are built into intelligent unmanned vehicle anchor node that comprises of locations, distances as well as SIDs. At that point LDM collection has been done into BS dependent upon SID that has been utilized for discovering the locality of the sensor nodes. 


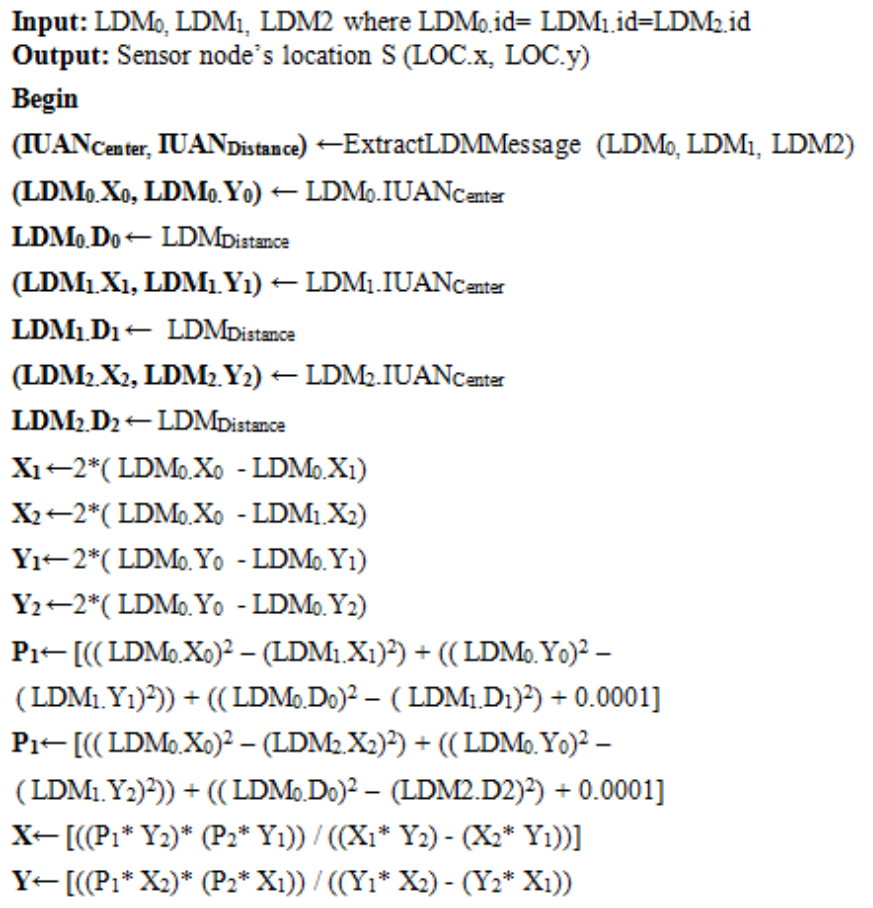

\section{EXPERIMENTAL RESULTS}

Our methodology evacuates the calculation overhead associated with localization at singular sensor nodes. In the wake of sending three SIDs, a sensor node won't fret over the localization procedure like the intelligent unmanned vehicle anchor node as well as central control station processes the sensor nodes locality. Be that as it may, existing calculations demand every sensor nodes towards executing overwhelming counts toward discover its location. These methodologies build the localization inclusion. Into current plans, the sensor node has been obliged for getting the radio guides as of identical airborne anchors, where it's not in any way conceivable since the direction of the flying anchor is not effective.

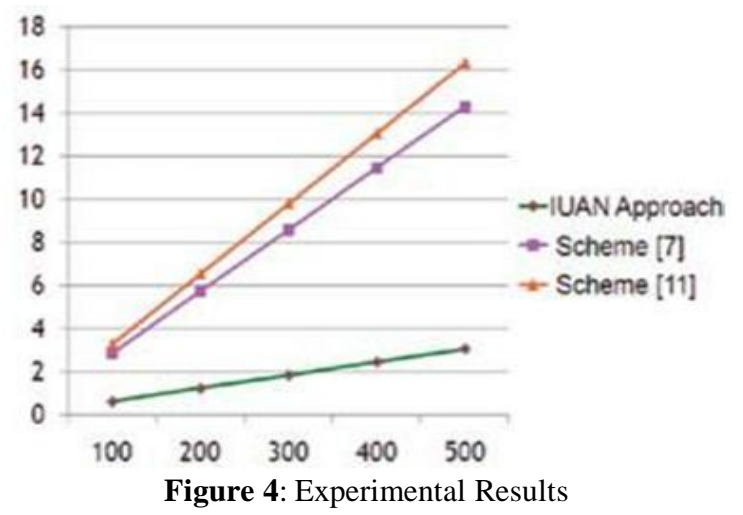

\section{CONCLUSION}

Intelligent unmanned vehicle anchor node -dependent localization approaches are projected for moderating the vitality into armed sensor network. The projected localization approaches lessen the correspondence operating cost as well as evacuates the calculation rate on every sensor nodes, accordingly diminishes the general vitality utilization. The Intelligent unmanned vehicle anchor node method moves the localization overhead as of sensor node toward the amazing central control station, such as the central control station figures the locality of sensor node utilizing ILA calculation through small calculation cost.

\section{REFERENCES}

1. Aguiar, ABD, Neto, ADMS, Pinheiro, PR \& Coelho, ALV. Applicability of a novel integer programming model for wireless sensor networks. Int. J. Comput. Sci. Info. Security, 2009, 3(1), 1-7.

2. Han, G, Xu, H, Duong, TQ, Jiang, J \& Hara, T. Localization algorithms of Wireless Sensor Networks: A survey. Telecommun. Sys., 2013, 52(4), 2419-2436. doi: 10.1007/s11235-011-9564-7.

3. $\mathrm{Ou}, \mathrm{CH} \& \mathrm{Ssu}, \mathrm{KF}$. Sensor position determination with flying anchor in three dimensional wireless sensor networks. IEEE Trans. Mobile Comput., 2008, 7(9), 1084-1097. https://doi.org/10.1109/TMC.2008.39

4. Liao, WH, Lee, YC \& Kedia, SP. Mobile anchor positioning for wireless sensor networks. IET Commun., 2011, 5(7), 914- 921.

5. Sheu, JP, Hu, WK \& Lin, JC. Distributed localization scheme for mobile sensor networks. IEEE Trans. Mobile Comput., 2010, 9(4), 516-526.

6. Pescaru, D. \& Curiac, D.I. Anchor node localization for wireless sensor networks using video and compass information fusion. Sensors, 2014, 14, 4211-4224.

7. M Selvi, P M Joe Prathap, "Analysis \& Classification of Secure Data Aggregation in Wireless Sensor Networks", International Journal of Engineering and Advanced Technology, Volume-8 Issue-4, April 2019, pp.1404-1407.

8. G. Ramprabu, S. Nagarajan, "Design and Analysis of Novel Modified Cross Layer Controller for WMSN", Indian Journal of Science and Technology, Volume 8, Issue 4, March 2015, pp.438-444.

9. A. Nageswar Rao , B. Rajendra Naik , L. Nirmala Devi, "Location Aware Relay Node Placement for Energy Constrained Wireless Sensor Networks", International Journal of Advanced Trends in Computer Science and Engineering, Volume 8, No.3, May - June 2019, pp.519-526. https://doi.org/10.30534/ijatcse/2019/28832019

10. Yung-Fa Huang, Jong-Shin Chen, Li-Ming Wang, "Performance of Transmission Delay and Energy Consumption of Adaptive Listening Mechanism for Wireless Sensor Networks", International Journal of Advanced Trends in Computer Science and Engineering, Volume 8, No.6, November - December 2019, pp.3215-3220.

https://doi.org/10.30534/ijatcse/2019/88862019 